\title{
Actual consumption amount of personal care products reflecting Japanese cosmetic habits
}

\author{
Masahiko Yamaguchi1,2, Daisuke Araki ${ }^{1,3}$, Takeshi Kanamori 1,4, Yasuko Okiyama ${ }^{1,5}$, \\ Hirokazu Seto1,6, Masaki Uda1,7, Masahito Usami1,8, Yutaka Yamamoto1,9, \\ Takuji Masunaga ${ }^{1,10}$ and Hitoshi Sasa ${ }^{1,2}$ \\ ${ }^{1}$ Safety Subcommittee, Japan Cosmetic Industry Association, 6th Fl., Metro City Kamiyacho, \\ 5-1-5, Toranomon, Minato-ku, Tokyo 105-0001, Japan \\ ${ }^{2}$ Global Innovation Center, Shiseido co., Ltd, 2-2-1, Hayabuchi, Tsudzuki-ku, Yokohama, Kanagawa, 224-8558, Japan \\ ${ }^{3}$ Quality Assurance Department, Kanebo Cosmetics Inc., 5-3-28, Kotobukicho, Odawara, Kanagawa, 250-0002, Japan \\ ${ }^{4}$ \&\&D Promotion Center, Sunstar Group, 3-1, Asahi-machi, Takatsuki, Osaka, 569-1195, Japan \\ ${ }^{5}$ \& I Center, Nihon L'Oréal K.K., 3-2-1, Sakado, Takatsu-ku, Kawasaki, Kanagawa, 213-0012, Japan \\ ${ }^{6}$ Reseach and Development, Procter and Gamble Japan, 7-1-18, Onoe-Dori, Chuo-ku, Kobe, Hyogo, 651-0088, Japan \\ ${ }^{7}$ Research Institute, FANCL Corporation, 12-13, Kamishinano, Totsuka-ku, Yokohama, Kanagawa, 244-0806, Japan \\ ${ }^{8}$ GENERAL RESEARCH\&DEVELOPMENT INSTITUTE, Hoyu co., Ltd., 1-12, Roboku, Nagakute, Aichi, 480-1136, Japan \\ ${ }^{9}$ Product Planning and Development Group, Noevir Co., Ltd., \\ 6-13-1, Minatojimanakamachi, Chuo-ku, Kobe, Hyogo, 650-8521, Japan \\ ${ }^{10}$ Research Laboratories, KOSÉ Corporation, 48-18, Sakae-cho, Kita-ku, Tokyo, 114-0005, Japan
}

[Recommended by Takemi Yoshida]

(Received August 8, 2017; Accepted October 6, 2017)

\begin{abstract}
Safety assessments of cosmetics are carried out by identifying possible harmful effects of substances in cosmetic products and assessing the exposure to products containing these substances. The present study provided data on the amounts of cosmetic products consumed in Japan to enhance and complement the existing data from Europe and the United States, i.e., the West. The outcomes of this study increase the accuracy of exposure assessments and enable more sophisticated risk assessment as a part of the safety assessment of cosmetic products. Actual amounts of products applied were calculated by determining the difference in the weight of products before and after use by approximately 300 subjects. The results of the study of skincare products revealed that in comparison with the West, large amounts of lotions and emulsions were applied, whereas lower amounts of cream and essence were applied in Japan. In the study of sunscreen products, actual measured values during outdoor leisure use were obtained, and these were lower than the values from the West. The study of the use of facial mask packs yielded data on typical Japanese sheet-type impregnated masks and revealed that high amounts were applied. Furthermore, data were obtained on cleansing foams, makeup removers and makeup products. The data from the present study enhance and complement existing information and will facilitate more sophisticated risk assessments. The present results should be extremely useful in safety assessments of newly developed cosmetic products and to regulatory authorities in Japan and around the world.
\end{abstract}

Key words: Cosmetics, Exposure assessment, Applied amount, Usage frequency, Seasonal fluctuation, Safety assessment

\section{INTRODUCTION}

Cosmetics are a class of personal care products. They are widely used, mainly by women, and are applied directly to the skin. Healthy people use cosmetics with the aim of improving their quality of life on a continual, daily basis over extended periods of time; therefore, it is important to ensure the safety of these products. In Japan,

Correspondence: Masahiko Yamaguchi (E-mail: masahiko.yamaguchi@to.shiseido.co.jp) 
some problems with cosmetic products have occurred in the past due to hazardous ingredients or impurities, such as basic lead carbonate (white lead), bithionol, or Sudan I (Takano, 2015). More recently, there have been adverse health effects resulting from the use of cosmetics containing hydrolyzed wheat protein (Chinuki et al., 2011) and rhododenol (Nishigori et al., 2015; Tokura et al., 2015). In Europe as well, allergies to methylisothiazolinone are so widespread as to be described as an "epidemic" (Lundov et al., 2013). Therefore, safety assessment of cosmetics is becoming an increasingly important issue on a global level.

The parameters evaluated in assessing the safety of cosmetics primarily involve topical toxicity, such as sensitization and irritation, and systemic toxicity, such as repeated-dose toxicity. Topical toxicity is often assessed in terms of composition concentration, and this can be converted to exposure per unit surface area. It has been reported that persons diagnosed with rhododenol-induced leukoderma use up to five different products (Aoyama et al., 2014), suggesting a relationship between the skin disorder and exposure per unit surface area. With systemic toxicity, exposure per kg of body weight is an important parameter. Risk is determined by carrying out hazard assessment of the component ingredients and comparing and integrating the details of exposure assessments for products containing these ingredients. Cosmetics contain many different ingredients, including oil-based raw materials, surfactants, high-molecular-weight compounds, ultraviolet absorbers, sequestering agents, pigments, and fragrances. As there are numerous product categories corresponding to the different modes of application, such as skincare, makeup, or rinse-off products, all of which differ with respect to site, quantity, and method of use, there are therefore a wide range of exposure scenarios that can be envisaged when conducting exposure assessments for cosmetic ingredients. Data on the amounts used are necessary for exposure assessment, and safety assessors often use data such as those provided by the European Commission's Scientific Committee on Consumer Safety (SCCS, 2012) or the United States Environmental Protection Agency (US-EPA, 2011). However, there are products that are not covered by existing exposure data, and cosmetics practices differ between countries and regions. For these reasons, Japan-specific estimates of cosmetic use are needed.

In 2012, the Subcommittee on Safety Measurements of the Committee on the Safety of Drugs of the Pharmaceutical Affairs and Food Sanitation Council carried out an assessment of exposure to polychlorinated biphenyls (PCBs) contained in cosmetics in response to a report indicating that PCBs are present in some cosmetic products as unintended byproducts of the manufacturing process of organic pigments. However, as no data were available on the amounts of cosmetics used in Japan, the risk assessment had no choice but to be based on data from Europe. In order to assess the safety of chemical substances, it is essential to envisage exposure scenarios as accurately as possible across a range of everyday settings. However, it was likely that the amounts of cosmetics used in Europe were not adequate for use in risk assessments in Japan. Japan continues to lag behind Europe and the US, i.e. the West, in research on cosmetics exposure assessment, but considering the increasing globalization of products and the spread of product categories and cosmetic practices of a given country or region to other regions, exposure data for products of Japanese origin are needed. In addition, as such data are tremendously valuable for the authorities when reviewing quasi-drugs and positive lists of cosmetics, they also fulfill a social need. The SCCS Guidance for Europe and the EPA data for the US were released by official bodies using data obtained by the cosmetics industry; therefore, it was essential for the Japan Cosmetic Industry Association to carry out its own survey.

The aim of the present study was to survey the amounts of cosmetic products used in order to characterize cosmetics use in Japan. The study simultaneously acquired data on exposure to cosmetic products in Japan in order to obtain exposure information on categories for which the Western data are insufficient and to clarify differences between Japanese and the Western exposure data relating to categories that are common to these regions.

\section{MATERIALS AND METHODS}

\section{Study design}

Surveys of skincare products were carried out during summer (August 27-September 19, 2014) and winter (January 23-February 16, 2015). Surveys of sunscreen products, facial mask packs, makeup and rinse-off products were carried out during summer (July 10-August 28, 2015). The subjects were women living in the suburbs of Tokyo who were recruited with the cooperation of a private Japanese research agency.

The subject recruitment criteria were as follows.

Skincare products:

- Women aged 18-74 years;

- Non-users of all-in-one skincare products;

Non-users of spray-type skincare cosmetics;

- Daily users of at least three of the following: lotion, emulsion, cream, essence, makeup base; and 
Actual consumption amounts of cosmetic products

Do not use abundant lotion, emulsion, cream, essence, or makeup base on the neck or upper arms.

Essence was defined as a high-value-added product to supplement the efficacies or texture of other basic skincare items such as lotion and emulsion.

A total of 300 subjects were recruited, such that they could be stratified by age into 10 -year age groups of equal size: 18, 19 years (12 women); 20-29 years, 30-39 years, 40-49 years, 50-59 years, 60-69 years (52 women in each); and 70-74 years (28 women). Of the $300 \mathrm{sub}-$ jects, $262(87.3 \%)$ participated during both the summer and winter.

Sunscreen products, pack and mask, makeup products, rinse-off products:

- Women aged 18-69 years;

- Daily users of face or body sunscreen (except spray type);

- Users of packs or masks at least once per month; and

- Users of five or more of the following nine items five days or more per week: facial cleanser, makeup remover, foundation, lipstick, lip gloss, eyeshadow, eyebrow, eyeliner, and mascara.

A total of 300 subjects were recruited: 18,19 years $(20$ women); 20-29 years, 30-39 years, 40-49 years (60 women each); 50-59 years, 60-69 years (50 women each).

\section{Study procedure}

Subjects were asked to bring all their cosmetic products to the experiment venue, with the exception of facial mask packs, and each subject's cosmetics were individually weighed in their packaging using a precision laboratory balance (GF3000, A\&D Company, Limited, Tokyo, Japan), and the weights were recorded. The subjects were asked to use the products as normal for at least a 2-week period while keeping a diary of use, in which they entered details such as site of use and number of times used. At the end of the experiment, the weight of the remainder of each product was measured using the same balance, and the weights were recorded. For the survey of outdoor leisure use of sunscreen, possible participants from among the subjects were invited to take part. Information on the setting and number of applications of sunscreen was obtained, and the amount used was determined from the weight before and after use. For facial mask packs, subjects were asked to bring the products they normally used to the experiment venue, and they then used the masks or packs according to the directions. The amount of product assumed to have transferred from the mask to the subject's face was determined by measuring the weight before and after use. The number of times per month mask packs were used was assessed by a questionnaire.

\section{Data analysis}

The total amount of each product used during the study period was determined from the difference in weight at the start and end of the experiment. The amount applied per single application was calculated by dividing the total amount used during the study period by the number of applications; the amount applied per day was calculated by dividing the total amount used during the study period by the number of days; and the number of applications per day was calculated by dividing the total number of applications during the study period by the number of days. These procedures were carried out separately in summer and winter, and with skincare products, the summer and winter values were compared using the Brunner-Munzel test. In addition, for each type of cosmetic product, the total for each age group and the combined total for summer and winter were determined.

\section{RESULTS}

\section{Number of users by product}

The number of users of each product is shown in Table 1 . With skincare products, almost all subjects used lotion, and data on 284 items were obtained from 278 subjects during summer, whereas data on 304 items were obtained from 293 subjects during winter. Regarding the method of applying lotion, it was found that 82 of 284 (29\%) items were applied with cotton puffs during the summer survey, and 81 of 304 (27\%) items were applied with cotton puffs during the winter survey. With emulsions, data on 198 items from 190 subjects were obtained during summer, and data on 199 items from 194 subjects were obtained during winter. Regarding the method of applying emulsion, it was found that 23 of 198 (12\%) items were applied with cotton puffs during the summer survey, and 20 of $199(10 \%)$ items were applied with cotton puffs in winter. With creams, data on 141 items were obtained from 128 subjects during summer and on 162 items from 154 subjects during winter; with essence, data on 136 items from 126 subjects were obtained during summer and on 129 items from 123 subjects during winter; with makeup bases, data on 154 items were obtained from 152 subjects during summer and on 164 items from 163 subjects during winter.

In the surveys of sunscreens, data were obtained from 288 subjects of everyday sunscreen use and 122 subjects of outdoor leisure sunscreen use. Pack and mask use was almost exclusively sheet-type masks, and data were obtained from 263 subjects. Other types of packs and masks used included peel-off, wipe-off, and rinseoff types, but the data were not analyzed, as the total 
Table 1. Number of subjects list.

\begin{tabular}{|c|c|c|}
\hline Product type & Summer season & Winter season \\
\hline Lotion & $278(284)$ & $293(304)$ \\
\hline Hand use & $198(202)$ & $217(223)$ \\
\hline Cotton use & $80(82)$ & $79(81)$ \\
\hline Emulsion & $190(198)$ & $194(199)$ \\
\hline Hand use & $168(175)$ & $175(179)$ \\
\hline Cotton use & $23(23)$ & $19(20)$ \\
\hline Cream & $128(141)$ & $154(162)$ \\
\hline Essence & $126(136)$ & $123(129)$ \\
\hline Makeup base & $152(154)$ & $163(164)$ \\
\hline Sunscreen in leisure use & & $122(125)$ \\
\hline Sunscreen in daily use & & $288(346)$ \\
\hline Facial mask pack & & $263(263)$ \\
\hline Powder foundation & & $138(139)$ \\
\hline Liquid foundation & & $131(137)$ \\
\hline Eyeliner & & $141(158)$ \\
\hline Eyeshadow & & $210(260)$ \\
\hline Eyebrow & & $216(235)$ \\
\hline Mascara & & $174(186)$ \\
\hline Lipstick & & $202(256)$ \\
\hline Lip gloss & & $123(131)$ \\
\hline Cleansing foam & & $163(163)$ \\
\hline Makeup-remover & & $181(181)$ \\
\hline
\end{tabular}

The number of products used is shown in parentheses

was only 32 subjects for all of these types. For makeup products, sufficient subjects to allow data analysis were obtained for the various products. For facial cleansers, data on facial cleansing foam, the type most popular in Japan, were obtained from 163 subjects, but the total for lather, emulsion, mousse, and liquid types was only 30 subjects, so those data were not analyzed.

\section{Comparison of application methods}

Table 2 shows a comparison of data on lotions and emulsions when applied with the hands and when applied with cotton puffs. Comparison of the means and the medians for data from lotions demonstrated that the amount of lotion applied with cotton puffs was approximately 1.5 times greater than with the hands in both the amount applied per day and per single application, whereas with emulsions, the amount applied was around 1.2-1.7 times greater when the product was applied with cotton puffs. When lotion or emulsion is applied with cotton puffs, some of the product remains in the cotton puffs. This means that the amount applied did not reflect the actual exposure of the skin to the product. Therefore, lotions and emulsions were analyzed using only data for application of the product using the hands.

\section{Amount of sunscreen applied}

Analysis of sunscreens was carried out by combining all users, including subjects who used multiple products and subjects who applied sunscreen to different areas. Figure 1 shows the distribution of number of applications per day of sunscreen products for outdoor leisure, and the mode was less than 2 times per day. However, there were subjects who applied sunscreen up to 7 times per day. Table 3 shows data on the amount of sunscreen applied for outdoor leisure. The amount applied per single application was $2.16 \mathrm{~g}$ on a median basis and $4.93 \mathrm{~g}$ on the 90th percentile value. The amount applied per day was $3.58 \mathrm{~g}$ on a median basis and $8.35 \mathrm{~g}$ on the 90 th percentile value.

Table 4 shows data on the number of applications and the amount applied for daily use. Sunscreen was applied once per day in almost all subjects; amount applied per single application was $0.60 \mathrm{~g}$ on a median basis and 1.67 $\mathrm{g}$ on the 90th percentile value. The amount applied per day was $0.57 \mathrm{~g}$ on a median basis and $1.68 \mathrm{~g}$ on the 90 th percentile value. Daily use of sunscreen showed smaller median and 90th percentile values for amount applied per day and amount applied per single application than outdoor leisure use. 
Actual consumption amounts of cosmetic products

Table 2. Comparison of hand use and cotton use for the lotion and emulsion.

\begin{tabular}{|c|c|c|c|c|c|c|}
\hline & \multicolumn{2}{|c|}{$\begin{array}{l}\text { Number of applications } \\
\text { per day }\end{array}$} & \multicolumn{2}{|c|}{$\begin{array}{l}\text { Amount of product per } \\
\text { application (grams) }\end{array}$} & \multicolumn{2}{|c|}{$\begin{array}{l}\text { Amount of product } \\
\text { per day (grams) }\end{array}$} \\
\hline & Hand use & Cotton use & Hand use & Cotton use & Hand use & Cotton use \\
\hline \multicolumn{7}{|l|}{ Lotion } \\
\hline \multicolumn{7}{|l|}{ Summer season } \\
\hline $\mathrm{N}$ & 202 & 82 & 202 & 82 & 202 & 82 \\
\hline Mean & 1.9 & 1.9 & 0.82 & 1.20 & 1.53 & 2.23 \\
\hline S.D. & 0.4 & 0.3 & 0.48 & 0.60 & 0.97 & 1.23 \\
\hline Median & 2.0 & 2.0 & 0.72 & 1.07 & 1.30 & 1.97 \\
\hline The ratio of the mean value & & 1.0 & & 1.5 & & 1.5 \\
\hline The ratio of the median value & & 1.0 & & 1.5 & & 1.5 \\
\hline \multicolumn{7}{|l|}{ Winter season } \\
\hline $\mathrm{N}$ & 223 & 81 & 223 & 81 & 223 & 81 \\
\hline Mean & 1.9 & 1.9 & 0.90 & 1.32 & 1.72 & 2.54 \\
\hline S.D. & 0.3 & 0.2 & 0.56 & 0.81 & 1.10 & 1.61 \\
\hline Median & 2.0 & 2.0 & 0.75 & 1.13 & 1.41 & 2.15 \\
\hline The ratio of the mean value & & 1.0 & & 1.5 & & 1.5 \\
\hline The ratio of the median value & & 1.0 & & 1.5 & & 1.5 \\
\hline \multicolumn{7}{|l|}{ Emulsion } \\
\hline \multicolumn{7}{|l|}{ Summer season } \\
\hline $\mathrm{N}$ & 175 & 23 & 175 & 23 & 175 & 23 \\
\hline Mean & 1.6 & 1.7 & 0.44 & 0.69 & 0.69 & 1.19 \\
\hline S.D. & 0.5 & 0.4 & 0.37 & 0.57 & 0.52 & 1.01 \\
\hline Median & 1.9 & 2.0 & 0.37 & 0.61 & 0.58 & 0.92 \\
\hline The ratio of the mean value & & 1.1 & & 1.6 & & 1.7 \\
\hline The ratio of the median value & & 1.1 & & 1.6 & & 1.6 \\
\hline \multicolumn{7}{|l|}{ Winter season } \\
\hline $\mathrm{N}$ & 179 & 20 & 179 & 20 & 179 & 20 \\
\hline Mean & 1.7 & 1.8 & 0.48 & 0.65 & 0.83 & 1.13 \\
\hline S.D. & 0.4 & 0.4 & 0.33 & 0.50 & 0.58 & 0.91 \\
\hline Median & 2.0 & 2.0 & 0.40 & 0.52 & 0.67 & 0.84 \\
\hline The ratio of the mean value & & 1.1 & & 1.3 & & 1.4 \\
\hline The ratio of the median value & & 1.0 & & 1.3 & & 1.2 \\
\hline
\end{tabular}

\section{Amount of skincare products applied and comparison between summer and winter}

Table 5 shows the results of surveys during summer and winter of number of applications per day, amount applied per single application, and amount applied per day. The median values for number of applications per day were: 2.0 applications in both summer and winter for lotions, 1.9 applications in summer and 2.0 applications in winter for emulsions, 1.0 application in summer and 1.3 applications in winter for creams, 1.7 applications in summer and 1.8 applications in winter for essence, and 1.0 application in both summer and winter for makeup bases. Although the differences between the number of applications per day in summer and in winter were very small, there were statistically significant differences for emulsions, creams, and makeup bases. The median values for amount applied per single application were:
$0.72 \mathrm{~g}$ in summer and $0.75 \mathrm{~g}$ in winter for lotions, $0.37 \mathrm{~g}$ in summer and $0.40 \mathrm{~g}$ in winter for emulsions, $0.22 \mathrm{~g}$ in summer and $0.25 \mathrm{~g}$ in winter for creams, $0.20 \mathrm{~g}$ in summer and $0.22 \mathrm{~g}$ in winter for essence, and $0.13 \mathrm{~g}$ in summer and $0.15 \mathrm{~g}$ in winter for makeup bases. The differences between the amount applied per single application in summer and winter were very small, and the amount applied per single application was significantly greater in winter only for creams. The median values for amount applied per day were: $1.30 \mathrm{~g}$ in summer and $1.41 \mathrm{~g}$ in winter for lotions, $0.58 \mathrm{~g}$ in summer and $0.67 \mathrm{~g}$ in winter for emulsions, $0.26 \mathrm{~g}$ in summer and $0.36 \mathrm{~g}$ in winter for creams, $0.27 \mathrm{~g}$ in summer and $0.34 \mathrm{~g}$ in winter for essence, and $0.12 \mathrm{~g}$ in summer and $0.15 \mathrm{~g}$ in winter for makeup bases. For all of these products, there was a tendency toward a greater amount applied per day in winter, and the amount applied per day was significantly greater 
M. Yamaguchi et al.

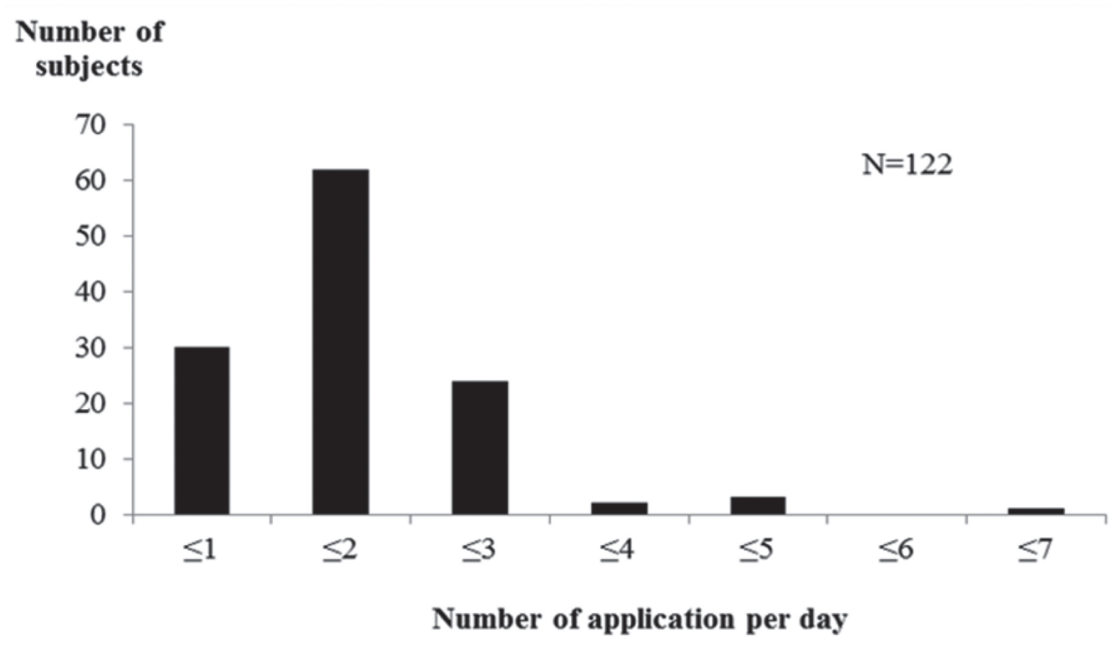

Fig. 1. Distribution of the number of applications per day on the leisure use sunscreen.

Table 3. Result of usage data on sunscreen products in leisure use.

\begin{tabular}{lcc}
\hline N & $\begin{array}{c}\text { Amount applied per application } \\
\text { (grams) }\end{array}$ & $\begin{array}{c}\text { Amount applied per day } \\
\text { (grams) }\end{array}$ \\
Mean & 122 & 122 \\
S.D. & 2.52 & 4.77 \\
Median & 1.64 & 4.29 \\
Minimum & 2.16 & 3.58 \\
Maximum & 0.14 & 0.25 \\
Percentiles & 8.00 & 28.80 \\
10th & & 1.06 \\
20th & 0.78 & 1.71 \\
30th & 1.12 & 2.34 \\
40th & 1.50 & 3.04 \\
50th & 1.73 & 3.58 \\
60th & 2.16 & 4.44 \\
70th & 2.68 & 5.93 \\
80th & 3.10 & 6.78 \\
90th & 3.63 & 8.35 \\
95th & 4.93 & 12.12 \\
99th & 5.75 & 27.69 \\
\hline
\end{tabular}

in winter for emulsions, creams, and makeup bases.

Figure 2 shows the distribution of amount applied per day. Neither summer nor winter appeared to exhibit a normal distribution, and although the differences were small, a tendency can be seen toward greater amounts applied in winter, consistent with the statistical test results.

\section{Actual usage by product category}

Number of applications per day, amount applied per application, and amount applied per day for skin- care products are shown in Tables 6, 7, and 8, respectively, combining the data for summer and winter. Median number of applications per day was approximately 2 for lotion, emulsion, and essence and approximately 1 for cream and makeup base. The amount applied per application on a median basis was: $0.74 \mathrm{~g}$ for lotion, $0.39 \mathrm{~g}$ for emulsion, $0.24 \mathrm{~g}$ for cream, $0.21 \mathrm{~g}$ for essence, and $0.14 \mathrm{~g}$ for makeup base; and the 90th percentile values were $1.62 \mathrm{~g}$ for lotion, $0.85 \mathrm{~g}$ for emulsion, $0.58 \mathrm{~g}$ for cream, $0.42 \mathrm{~g}$ for essence, and $0.29 \mathrm{~g}$ for makeup base. The 
Actual consumption amounts of cosmetic products

Table 4. Result of usage data on sunscreen products in daily use.

\begin{tabular}{lccc}
\hline & $\begin{array}{c}\text { Number of applications } \\
\text { per day }\end{array}$ & $\begin{array}{c}\text { Amount applied per } \\
\text { application (grams) }\end{array}$ & $\begin{array}{c}\text { Amount applied per } \\
\text { day (grams) }\end{array}$ \\
\hline N & 288 & 288 & 288 \\
Mean & 1.0 & 0.82 & 0.78 \\
S.D. & 0.3 & 0.77 & 0.75 \\
Median & 1.0 & 0.60 & 0.57 \\
Minimum & 0.1 & 0.00 & 0.00 \\
Maximum & 3.0 & 4.78 & 4.41 \\
Percentiles & & & 0.15 \\
10th & 0.7 & 0.16 & 0.21 \\
20th & 0.8 & 0.23 & 0.30 \\
30th & 0.9 & 0.33 & 0.42 \\
40th & 1.0 & 0.45 & 0.57 \\
50th & 1.0 & 0.60 & 0.69 \\
60th & 1.0 & 0.75 & 0.92 \\
70th & 1.0 & 0.97 & 1.14 \\
80th & 1.1 & 1.19 & 1.68 \\
90th & 1.3 & 1.67 & 2.55 \\
95th & 1.6 & 2.28 & 3.51 \\
99th & 1.9 & 3.67 & \\
\hline
\end{tabular}

Table 5. Comparison of summer and winter surveys.

\begin{tabular}{|c|c|c|c|c|c|c|c|c|c|c|}
\hline \multirow{2}{*}{$\begin{array}{l}\text { Product type } \\
\text { Survey season }\end{array}$} & \multicolumn{2}{|c|}{ Lotiona) } & \multicolumn{2}{|c|}{ Emulsiona) $^{\text {a) }}$} & \multicolumn{2}{|c|}{ Cream } & \multicolumn{2}{|c|}{ Essence } & \multicolumn{2}{|c|}{ Makeup base } \\
\hline & Summer & Winter & Summer & Winter & Summer & Winter & Summer & Winter & Summer & Winter \\
\hline \multicolumn{11}{|c|}{ Number of appications per day } \\
\hline $\mathrm{N}$ & 202 & 223 & 175 & 179 & 141 & 162 & 136 & 129 & 154 & 164 \\
\hline Mean & 1.9 & 1.9 & 1.6 & 1.7 & 1.3 & 1.5 & 1.5 & 1.5 & 0.9 & 1.0 \\
\hline S.D. & 0.4 & 0.3 & 0.5 & 0.4 & 0.5 & 0.5 & 0.5 & 0.5 & 0.2 & 0.1 \\
\hline Median & 2.0 & $2.0 \mathrm{n} . \mathrm{s}$. & 1.9 & $2.0 *$ & 1.0 & $1.3^{*}$ & 1.7 & $1.8 \mathrm{n} . \mathrm{s}$. & 1.0 & $1.0^{*}$ \\
\hline Minimum & 0.9 & 0.9 & 0.3 & 0.8 & 0.2 & 0.8 & 0.4 & 0.2 & 0.1 & 0.2 \\
\hline Maximum & 4.0 & 3.7 & 4.0 & 3.7 & 2.4 & 2.6 & 2.2 & 2.6 & 2.1 & 1.6 \\
\hline \multicolumn{11}{|c|}{ Amount applied per application (grams) } \\
\hline $\mathrm{N}$ & 202 & 223 & 175 & 179 & 141 & 162 & 136 & 129 & 154 & 164 \\
\hline Mean & 0.82 & 0.90 & 0.44 & 0.48 & 0.28 & 0.32 & 0.24 & 0.26 & 0.18 & 0.18 \\
\hline S.D. & 0.48 & 0.56 & 0.37 & 0.33 & 0.24 & 0.23 & 0.20 & 0.21 & 0.19 & 0.13 \\
\hline Median & 0.72 & 0.75 n.s. & 0.37 & 0.40 n.s. & 0.22 & $0.25^{*}$ & 0.20 & 0.22 n.s. & 0.13 & 0.15 n.s. \\
\hline Minimum & 0.12 & 0.09 & 0.04 & 0.05 & 0.01 & 0.02 & 0.02 & 0.01 & 0.01 & 0.01 \\
\hline Maximum & 2.84 & 3.14 & 3.33 & 2.14 & 1.36 & 1.45 & 1.74 & 1.51 & 1.71 & 1.02 \\
\hline \multicolumn{11}{|c|}{ Amount applied per day (grams) } \\
\hline $\mathrm{N}$ & 202 & 223 & 175 & 179 & 141 & 162 & 136 & 129 & 154 & 164 \\
\hline Mean & 1.53 & 1.72 & 0.69 & 0.83 & 0.35 & 0.47 & 0.33 & 0.41 & 0.16 & 0.17 \\
\hline S.D. & 0.97 & 1.10 & 0.52 & 0.58 & 0.34 & 0.35 & 0.23 & 0.38 & 0.18 & 0.13 \\
\hline Median & 1.30 & 1.41 n.s. & 0.58 & $0.67^{*}$ & 0.26 & $0.36^{*}$ & 0.27 & 0.34 n.s. & 0.12 & $0.15^{*}$ \\
\hline Minimum & 0.19 & 0.18 & 0.03 & 0.05 & 0.01 & 0.02 & 0.02 & 0.01 & 0.01 & 0.01 \\
\hline Maximum & 6.61 & 6.28 & 3.91 & 3.53 & 2.20 & 1.88 & 1.20 & 2.74 & 1.62 & 1.07 \\
\hline
\end{tabular}

a): Hand use

n.s.: No significant difference in median values of summer and winter

*: Significantly different from median values of summer and winter, $\mathrm{P}<0.05$ (Brunner-Munzel test)

amount applied per day on a median basis was: $1.36 \mathrm{~g}$ for lotion, $0.64 \mathrm{~g}$ for emulsion, $0.30 \mathrm{~g}$ for cream, $0.31 \mathrm{~g}$ for essence, and $0.13 \mathrm{~g}$ for makeup base; and the 90th per- centile values were $2.99 \mathrm{~g}$ for lotion, $1.46 \mathrm{~g}$ for emulsion, $0.84 \mathrm{~g}$ for cream, $0.72 \mathrm{~g}$ for essence, and $0.27 \mathrm{~g}$ for makeup base. 
M. Yamaguchi et al.

(A) Lotion

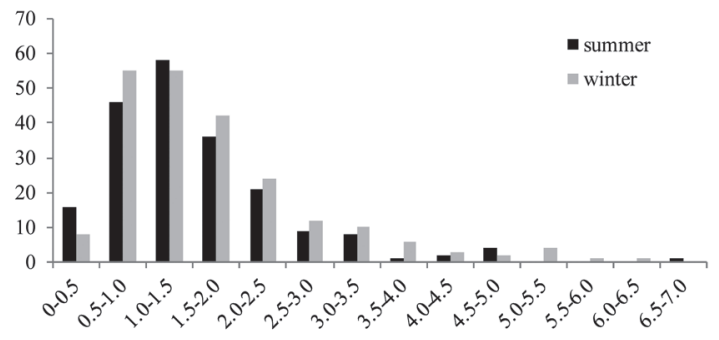

(B) Emulsion

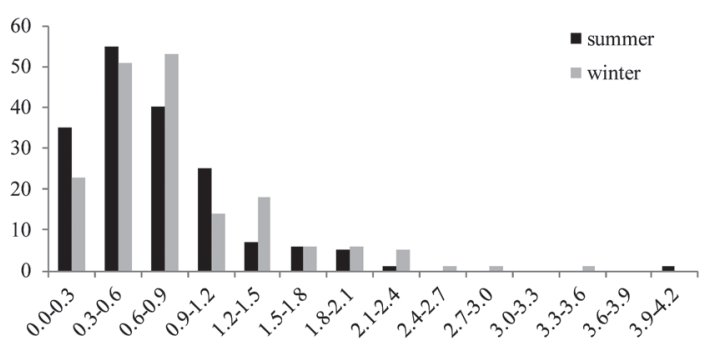

(D) Essence

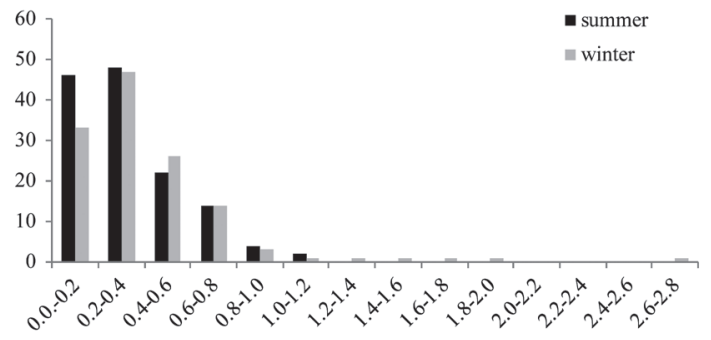

(E) Makeup base

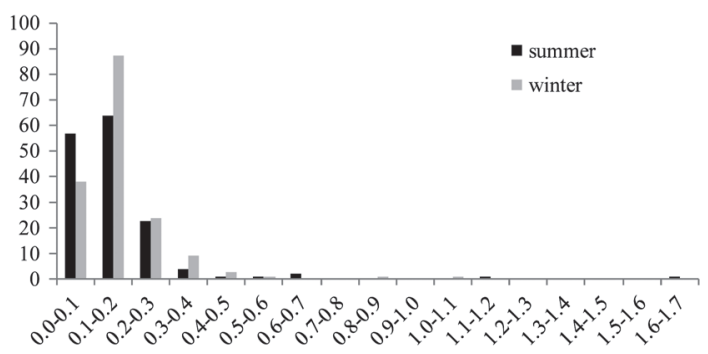

(C) Cream

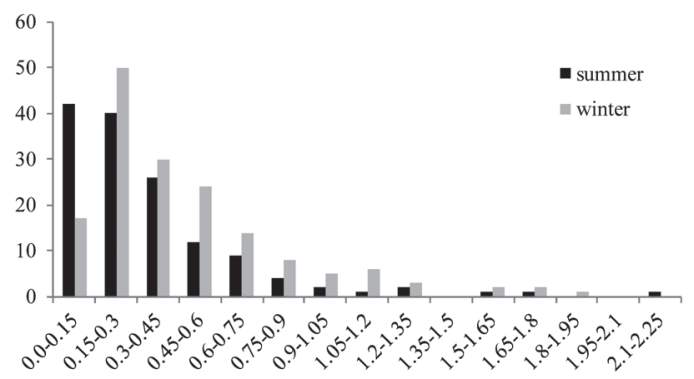

Fig. 2. Distribution of amount applied per day for skincare cosmetics. Horizontal and vertical axes indicated the amount applied per day (g/day) and number of product, respectively. (A), lotion; (B), emulsion; (C), cream; (D), essence; (E), makeup base.

Table 9 shows frequency distributions of the number of applications per month, the number of applications per day, and the amount used per single application for facial mask packs. The maximum value for number of sheet mask applications per month obtained from the questionnaire was 30 , or 1 application per day. The median was 4 applications per month, or 1 application per week. The values for amount applied per single application were: mean, $4.95 \mathrm{~g}$; median, $4.66 \mathrm{~g}$; and 90th percentile, $7.19 \mathrm{~g}$.

Tables 10-12 show the number of applications per day, amount applied per application, and amount applied per day for makeup and rinse-off products. For products used around the eyes (eyeliner, eyeshadow, eyebrow, and mascara), the mean, median, and 90th percentile of number of applications per day were in the range $0.8-1.2$. For products applied to the lips (lipstick, lip gloss), these values were in the range $1.0-2.0$, indicating a greater frequency of application than products used around the eyes. These values were in the range 0.9-1.0 for makeup remover and 1.2-1.9 for cleansing foam, indicating a greater frequency of use of cleansing foam. Makeup products used around the eyes were used roughly once per day, so for these products, there were no great differences between the amount applied per application and the amount applied per day. For example, in the case of makeup products, the median value was $0.011 \mathrm{~g}$ per application versus $0.009 \mathrm{~g}$ per day for mascara, in the rinse-off products, the median value was $0.76 \mathrm{~g}$ per application versus $0.92 \mathrm{~g}$ per day for 
Actual consumption amounts of cosmetic products

Table 6. Number of applications per day (skincare products).

\begin{tabular}{|c|c|c|c|c|c|}
\hline Product type & Lotiona) & Emulsiona) & Cream & Essence & Makeup base \\
\hline $\mathrm{N}$ & 425 & 354 & 303 & 265 & 318 \\
\hline Mean & 1.9 & 1.7 & 1.4 & 1.5 & 0.9 \\
\hline S.D. & 0.3 & 0.5 & 0.5 & 0.5 & 0.2 \\
\hline Median & 2.0 & 1.9 & 1.1 & 1.7 & 1.0 \\
\hline Minimum & 0.9 & 0.3 & 0.2 & 0.2 & 0.1 \\
\hline Maximum & 4.0 & 4.0 & 2.6 & 2.6 & 2.1 \\
\hline \multicolumn{6}{|l|}{ Percentile } \\
\hline 10th & 1.5 & 1.0 & 0.9 & 0.9 & 0.8 \\
\hline 20th & 1.8 & 1.1 & 1.0 & 1.0 & 0.9 \\
\hline 30 th & 1.9 & 1.5 & 1.0 & 1.0 & 0.9 \\
\hline 40th & 2.0 & 1.9 & 1.1 & 1.1 & 1.0 \\
\hline 50 th & 2.0 & 1.9 & 1.1 & 1.7 & 1.0 \\
\hline 60th & 2.0 & 2.0 & 1.7 & 1.9 & 1.0 \\
\hline 70th & 2.0 & 2.0 & 2.0 & 2.0 & 1.0 \\
\hline 80th & 2.0 & 2.0 & 2.0 & 2.0 & 1.1 \\
\hline 90th & 2.0 & 2.0 & 2.0 & 2.0 & 1.1 \\
\hline 95th & 2.1 & 2.1 & 2.0 & 2.0 & 1.1 \\
\hline 99th & 2.8 & 2.2 & 2.2 & 2.2 & 1.5 \\
\hline
\end{tabular}

a): Hand use

Table 7. Amount applied per application (skincare products).

\begin{tabular}{lccccc}
\hline Product type & Lotion $^{\text {a) }}$ & Emulsion $^{\text {a) }}$ & Cream & Essence & Makeup base \\
\hline N & 425 & 354 & 303 & 265 & 318 \\
Mean & 0.86 & 0.46 & 0.30 & 0.25 & 0.18 \\
S.D. & 0.52 & 0.35 & 0.24 & 0.20 & 0.16 \\
Median & 0.74 & 0.39 & 0.24 & 0.21 & 0.14 \\
Minimum & 0.09 & 0.04 & 0.01 & 0.01 & 0.01 \\
Maximum & 3.14 & 3.33 & 1.45 & & 1.74 \\
Percentile & & & & 0.08 & 0.06 \\
$\quad$ 10th & 0.37 & 0.15 & 0.08 & 0.12 & 0.09 \\
20th & 0.46 & 0.23 & 0.13 & 0.15 & 0.10 \\
30th & 0.53 & 0.29 & 0.17 & 0.18 & 0.12 \\
40th & 0.64 & 0.33 & 0.20 & 0.21 & 0.14 \\
50th & 0.74 & 0.39 & 0.24 & 0.25 & 0.16 \\
60th & 0.84 & 0.44 & 0.29 & 0.29 & 0.18 \\
70th & 0.96 & 0.50 & 0.35 & 0.34 & 0.22 \\
80th & 1.17 & 0.62 & 0.58 & 0.42 & 0.29 \\
90th & 1.62 & 0.85 & 0.81 & 1.00 & 0.39 \\
95th & 1.97 & 1.08 & & & (unit: grams) \\
99th & 2.66 & 1.70 & & &
\end{tabular}

cleansing foam, which were only about $20 \%$ differences.

\section{DISCUSSION}

\section{Study method}

The present study adopted the method of requesting subjects to use the products they normally use. In a similar study, all subjects were provided with the same products
(Loretz et al., 2005). Although this method yielded data on the amount applied under uniform conditions, it may not have reflected the real-life amounts applied because of the effects of the subjects' preferences. We focused on obtaining information on the amounts applied of products that subjects normally use. Also, there are studies in which data on exposure to cosmetic products are displayed on the basis of amounts applied determined from 
M. Yamaguchi et al.

Table 8. Amount applied per day (skincare products).

\begin{tabular}{|c|c|c|c|c|c|}
\hline Product type & Lotion ${ }^{a}$ & Emulsiona) & Cream & Essence & Makeup base \\
\hline $\mathrm{N}$ & 425 & 354 & 303 & 265 & 318 \\
\hline Mean & 1.63 & 0.76 & 0.41 & 0.37 & 0.17 \\
\hline S.D. & 1.05 & 0.55 & 0.35 & 0.32 & 0.15 \\
\hline Median & 1.36 & 0.64 & 0.30 & 0.31 & 0.13 \\
\hline Minimum & 0.18 & 0.03 & 0.01 & 0.01 & 0.01 \\
\hline Maximum & 6.61 & 3.91 & 2.20 & 2.74 & 1.62 \\
\hline \multicolumn{6}{|l|}{ Percentile } \\
\hline 10th & 0.64 & 0.22 & 0.09 & 0.08 & 0.06 \\
\hline 20th & 0.84 & 0.34 & 0.16 & 0.15 & 0.08 \\
\hline 30 th & 1.01 & 0.45 & 0.21 & 0.20 & 0.10 \\
\hline 40th & 1.15 & 0.53 & 0.26 & 0.24 & 0.12 \\
\hline 50 th & 1.36 & 0.64 & 0.30 & 0.31 & 0.13 \\
\hline 60 th & 1.54 & 0.74 & 0.37 & 0.35 & 0.16 \\
\hline 70th & 1.84 & 0.86 & 0.48 & 0.44 & 0.18 \\
\hline 80th & 2.22 & 1.10 & 0.61 & 0.55 & 0.21 \\
\hline 90th & 2.99 & 1.46 & 0.84 & 0.72 & 0.27 \\
\hline 95th & 3.72 & 1.83 & 1.12 & 0.82 & 0.35 \\
\hline 99th & 5.23 & 2.49 & 1.69 & 1.62 & 0.79 \\
\hline
\end{tabular}

Table 9. Amount applied data and number of applications per day in facial mask pack.

\begin{tabular}{lccc}
\hline & $\begin{array}{c}\text { Number of application } \\
\text { per day }\end{array}$ & $\begin{array}{c}\text { Number of application } \\
\text { per month }\end{array}$ & $\begin{array}{c}\text { Amount applied } \\
\text { per application (grams) }\end{array}$ \\
\hline $\mathrm{N}$ & $223^{\mathrm{a})}$ & $223^{\mathrm{a}}$ & 263 \\
Mean & 0.18 & 5.3 & 4.95 \\
S.D. & 0.17 & 5.1 & 2.21 \\
Median & 0.13 & 4.0 & 4.66 \\
Minimum & 0.03 & 1.0 & 1.44 \\
Maximum & 1.00 & 30.0 & 21.93 \\
Percentiles & & & 2.57 \\
10th & 0.03 & 1 & 3.26 \\
20th & 0.07 & 2 & 3.89 \\
30th & 0.07 & 2 & 4.37 \\
40th & 0.10 & 3 & 4.66 \\
50th & 0.13 & 4 & 5.10 \\
60th & 0.13 & 4 & 5.44 \\
70th & 0.13 & 4 & 6.12 \\
80th & 0.27 & 8 & 8.19 \\
90th & 0.40 & 12 & 12.08 \\
95th & 0.40 & 12 & 30 \\
99th & 1.00 & 30 & \\
\hline
\end{tabular}

a): The number of subject answering the questionnaire is 223 .

interviews with subjects (Park et al., 2015; Bernard et al., 2016). The interview method enables studies to enroll over 1,000 subjects, but it does not provide accurate values on amounts applied. With our data, the number of subjects was not high, but we weighed the products that the subjects used through preference in order to obtain accurate values. These results therefore accurately reflect actu- al amounts applied, and from this perspective, the results are more meaningful than those of other studies.

With facial mask packs, the main products surveyed were single-use, sheet-type impregnated masks. When evaluating safety, the amount of the product that actually remains on the skin needs to be measured, so the sheets were weighed before and after use at the experiment ven- 
Actual consumption amounts of cosmetic products
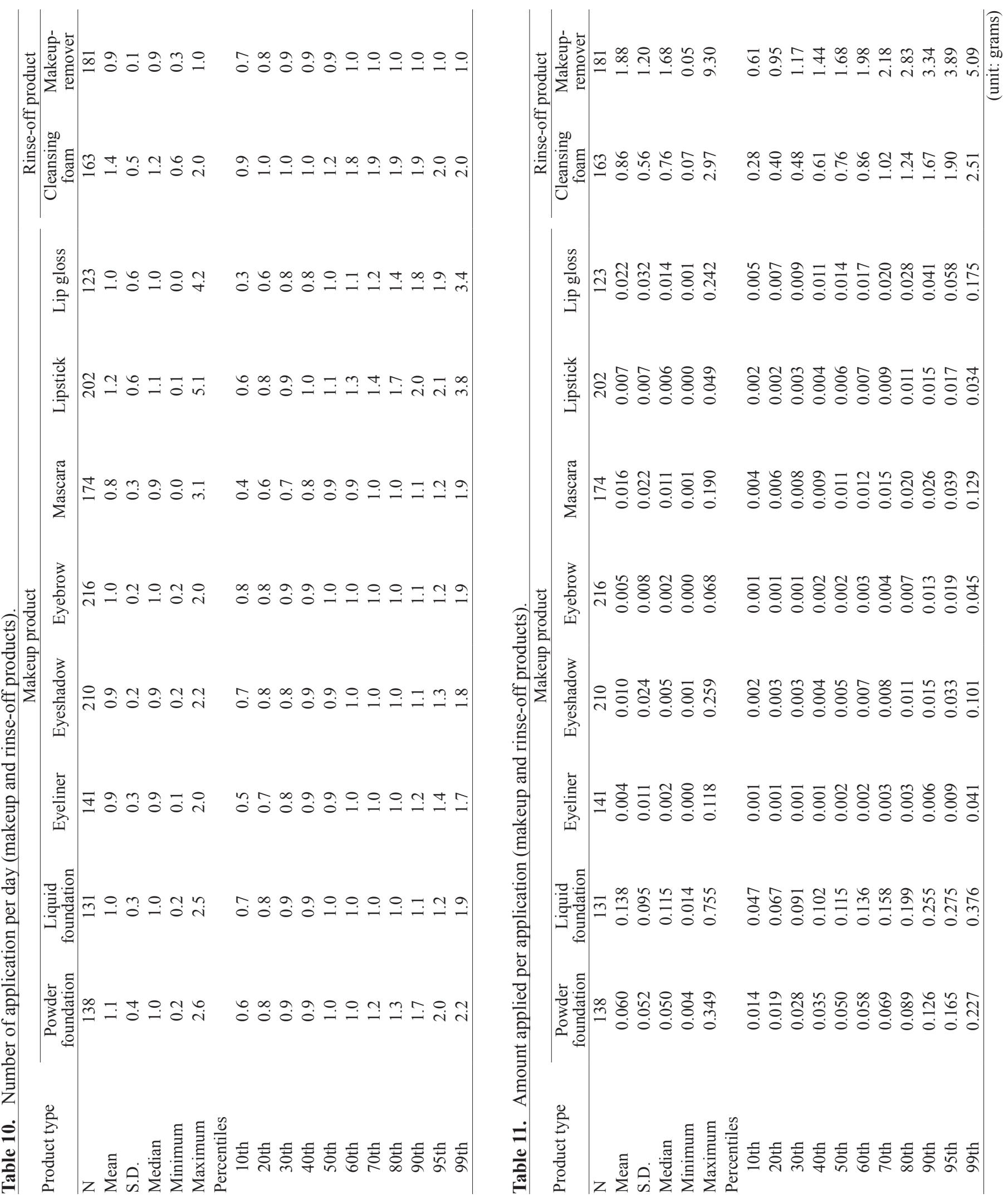
M. Yamaguchi et al.

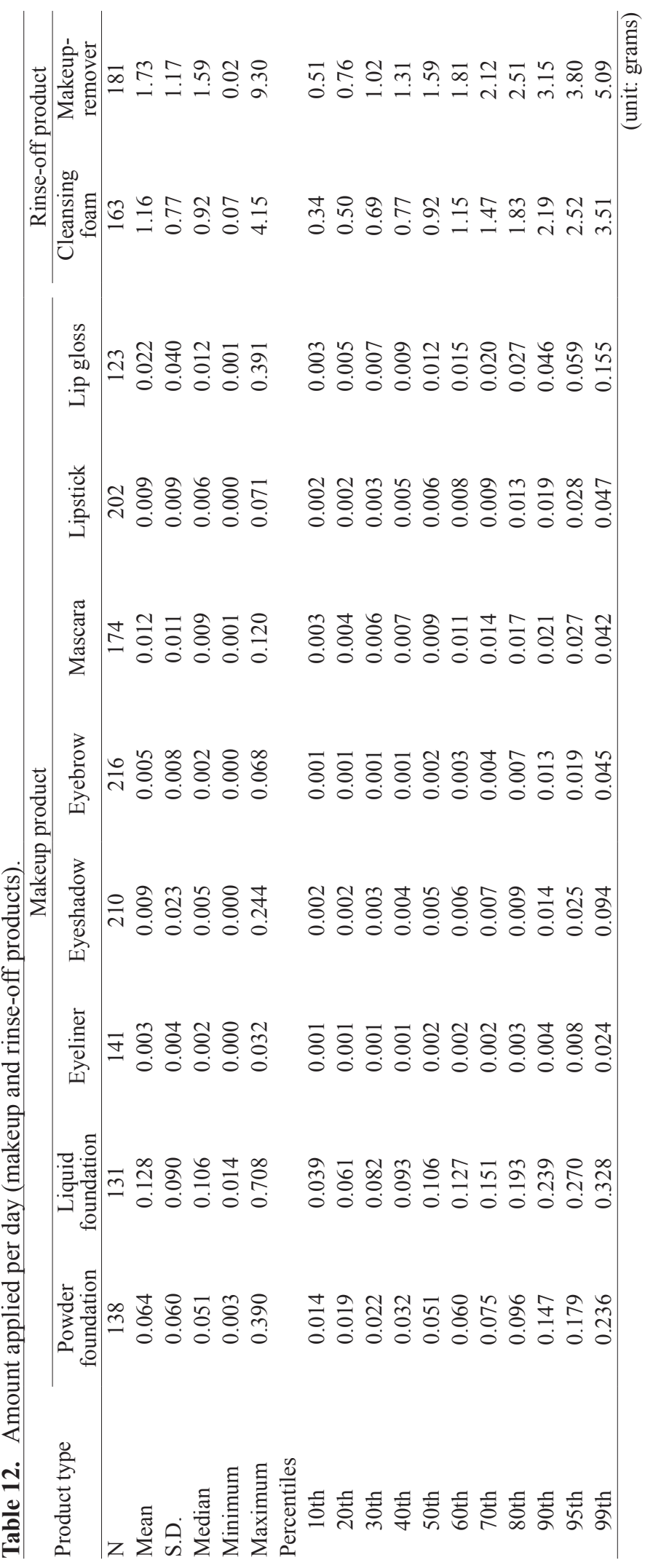

Vol. 42 No. 6 
Actual consumption amounts of cosmetic products

ue. The data are probably highly accurate because the products were used in the same way as usual.

In the present study, it was found that approximately $30 \%$ of the subjects for lotions and $10 \%$ of the subjects for emulsions used cotton puffs for application. When cotton puffs are used for application, some lotion or emulsion remains in the cotton puffs after use, so the data for the amount applied is greater than for the amount applied by hand, but this does not reflect the amount to which the skin is exposed. Consequently, only the data for application using the hands were adopted for analysis in the present study, and the data for application using cotton puffs are given for reference only. Experiments measuring the weight of product remaining in the cotton puffs are needed in order to determine the precise amount of exposure to the skin when the product is applied using cotton puffs, and this is an issue for a future study. Also, analysis by age was carried out, but no particular trends were discerned for any of the parameters (data not shown), so the data were handled with all age groups combined.

All of the skincare products showed an asymmetrical rather than normal distribution of the amount applied, meaning that the median or the 90th percentile would be appropriate for use in safety assessment.

The use of sunscreens, including those used on a daily basis, was surveyed during summer. This is considered an appropriate time to survey such products, as it is the period in which they are most widely used. Data on everyday use were obtained from 288 subjects, of which 57 used multiple products. This indicated that different products were used for the face and body. Because the purpose of the study was to reflect actual usage in order to assess systemic exposure dose (SED), the data from these subjects were integrated into the totals. Although outdoor leisure use covers a wide variety of settings and application sites, and the amount applied likely differs in each setting, the data were uniformly integrated as outdoor leisure use and totaled in the present study. Using the 90th percentile for exposure assessment could cover outdoor leisure use with large amounts applied, but future investigations of total amounts applied by setting are needed.

\section{Seasonal fluctuations}

Since we thought that seasonal fluctuations could affect the amount of skincare cosmetics applied, the study of skincare cosmetics was carried out taking the seasons into account. Indeed, statistical data from the Japan Meteorological Agency (http://www.jma.go.jp/jma/en/Publications/publications.html) revealed that the average temperature in Tokyo was $27.7^{\circ} \mathrm{C}$ in August 2014 and $5.8^{\circ} \mathrm{C}$ in January 2015, indicating a marked seasonal difference. As this variation in the outside environment might be expected to influence the amounts of cosmetics applied, surveys of skincare products were carried out in summer and winter. According to Japan Meteorological Agency statistics, the mean daily temperature in Tokyo during the survey period was in the range $21.1-27.8^{\circ} \mathrm{C}$ during the summer period (August 27-September 19, 2014) and $2.0-9.8^{\circ} \mathrm{C}$ during the winter period (January 23-February 16, 2015). The temperature difference between the summer and winter survey periods was considered sufficient to enable investigation of seasonal fluctuations.

In the analysis of differences between summer and winter, emulsions and creams showed significantly greater values in winter than in summer for number of applications per day and amounts applied per day, and creams showed significantly greater values in winter than in summer for amount applied per application. Makeup bases showed significantly greater values in winter than in summer for amount applied per day and, although showed statistically significant difference between the number of applications per day in summer and in winter, it was considered that there was no definite meaning. Lotion and essence also showed a trend toward greater values in winter than summer for amount applied, although the differences were not significant. It therefore appears that a characteristic of skincare product use in Japan is a slight increase in amount applied in winter.

There thus appear to be seasonal fluctuations in Japan in the amounts of cosmetics applied. Nonetheless, as cosmetics are used throughout the year, it was considered appropriate to combine summer and winter data for handling in the assessment of safety.

\section{Comparison with the western data}

Table 13 shows a comparison of data for the product types surveyed in the present study with the following existing data: Loretz et al. (2005), also published in the Exposure Factors Handbook (US-EPA, 2011); Hall et al. (2007); data from the Cosmetic, Toiletry, and Fragrance Association (CTFA, 1983); data from Biesterbos et al. (2013) for the Netherlands; the SCCS Notes of Guidance for the Testing of Cosmetic Ingredients and their Safety Evaluation (SCCS, 2012); and the Cosmetics Fact Sheet (Dutch National Institute for Public Health and the Environment [RIVM], 2006). A considerable amount of data are available for creams, and in the present study, mean values were $0.30 \mathrm{~g} /$ application and $0.41 \mathrm{~g} / \mathrm{day}$, and 90th percentile values were $0.58 \mathrm{~g} /$ application and $0.84 \mathrm{~g} /$ day. In comparison, in the Exposure Factors Handbook, means are 0.6-1.22 g/application and $2.05 \mathrm{~g} / \mathrm{day}$, and 90th percentiles are $2.11 \mathrm{~g} /$ application and $3.50 \mathrm{~g} / \mathrm{day}$; in 
M. Yamaguchi et al.

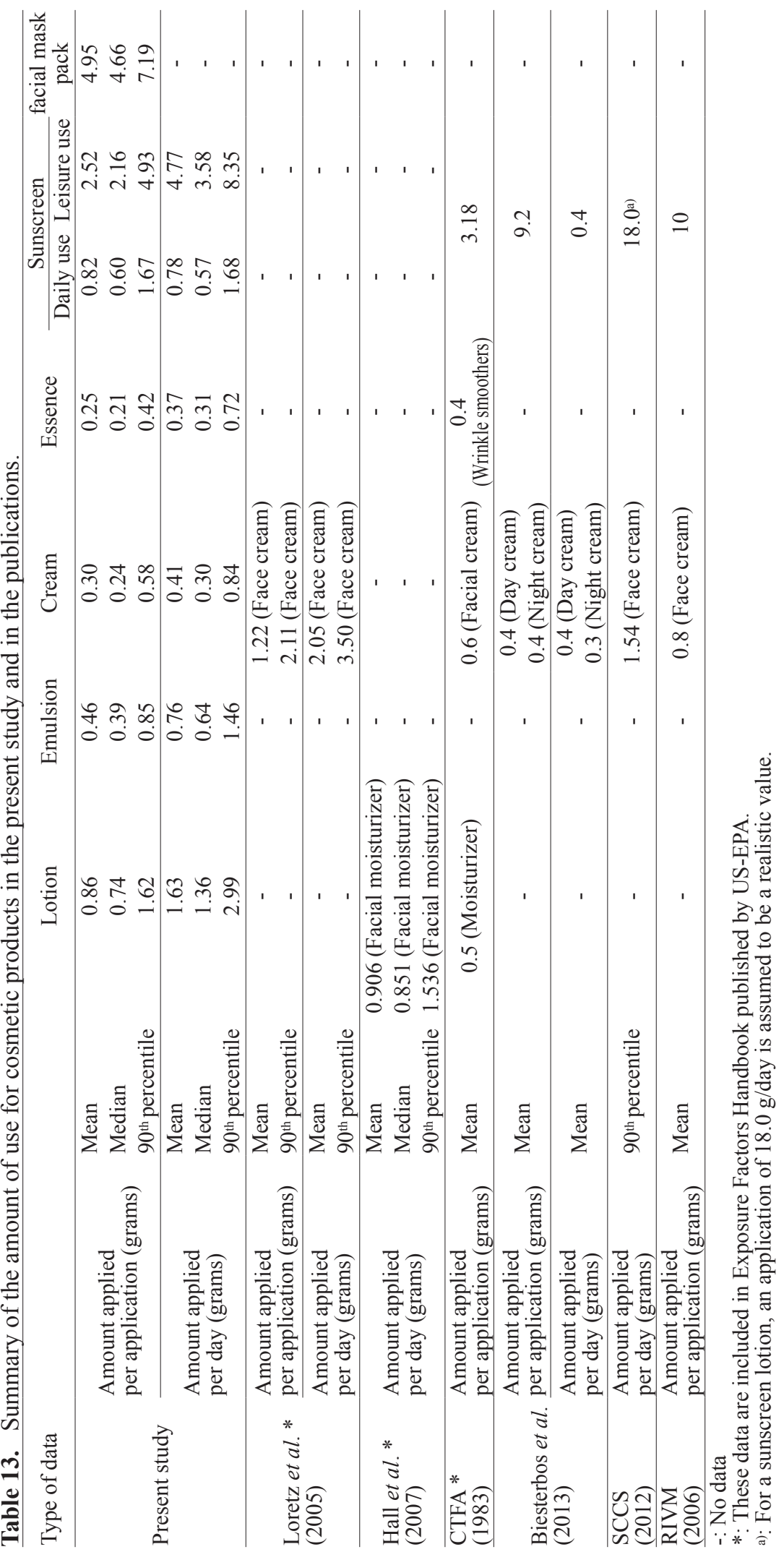

Vol. 42 No. 6 
Actual consumption amounts of cosmetic products

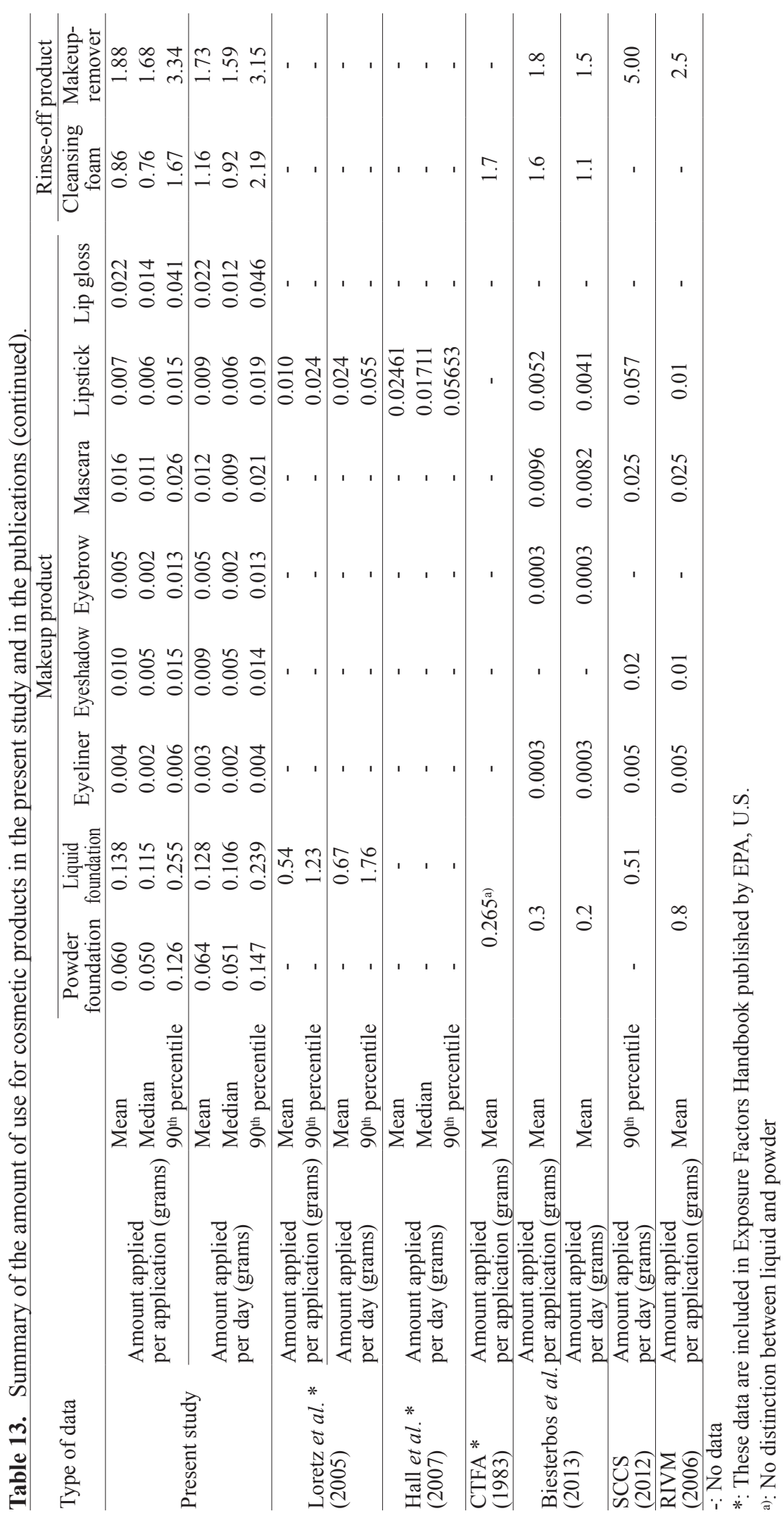


the data of Biesterbos et al., the mean is $0.4 \mathrm{~g} /$ application; in the Dutch RIVM data, the mean is $0.8 \mathrm{~g}$ /application; in the European Commission SCCS data, the 90th percentile is $1.54 \mathrm{~g} /$ day. Thus, the values obtained in the present study were lower than those of the existing data. With essence as well, the present data (mean $0.25 \mathrm{~g} / \mathrm{appli}$ cation) were lower than the US-EPA value (mean $0.4 \mathrm{~g}$ / application). In the present study, almost all subjects used lotions, and two-thirds of the subjects used emulsions. However, there are almost no data on amounts of these products applied available from the West. The only comparable data are US-EPA data for moisturizers, which show mean values of $0.5 \mathrm{~g} / \mathrm{application}$ and $0.906 \mathrm{~g} / \mathrm{day}$ and a 90th percentile of $1.536 \mathrm{~g} / \mathrm{day}$. In the present study, the mean value for lotions was $0.86 \mathrm{~g} /$ application and $1.63 \mathrm{~g} /$ day, and the 90th percentile was $2.99 \mathrm{~g} / \mathrm{day}$, and these values are higher than the US-EPA values. There is no usable information on the use of sheet masks in the West, but use of this type of product has increased not only in Japan but also across Asia, so it is likely that the data from the present study can be used effectively for exposure assessment. The above data suggest that the results of the present study reflect differences in customs relating to skincare products. There is a custom in Japan of using different skincare products on the face, as seen in the previously mentioned report by Aoyama et al. (2014), which indicated that up to five products containing rhododenol are used together. The present study has yielded data that will serve as reference for exposure assessment when products are used in combination.

The existing data on amounts of sunscreen applied do not make a clear distinction between daily use and outdoor leisure use, and although some reports have values that exceed the present study's results (SCCS, 2012; RIVM, 2006), there are also data that have considerably lower values for amount applied per day (Biesterbos et al., 2013). The SCCS explains its value of $18.0 \mathrm{~g} / \mathrm{day}$ thus: " $18.0 \mathrm{~g}$ per day is derived from the application of $0.5 \mathrm{mg} / \mathrm{cm}^{2}$ for the entire skin surface of an adult $\left(17,500 \mathrm{~cm}^{2}\right)$, twice a day, resulting in 17.5 gram in total per day per person." This figure was arrived at theoretically, and as the assumptions are on the safe side, it is probably higher than the actual amount applied. With regard to values that were lower than those of the present study, annual applied amounts were divided by the number of days of usage; therefore, assuming that there is a particular period of usage, the values are probably far too low (Biesterbos et al., 2013). The data from the present study are based on values actually measured during the period of sunscreen usage and are therefore the most appropriate data for carrying out safety assessments. However, because the number of subjects analyzed was insufficient and the method included uses other than application to the whole body, there remains the issue that direct comparison with the SCCS data is not possible. There is a need for further study.

The present results for makeup products that are applied around the eyes are very similar to existing data (Biesterbos et al., 2013; SCCS, 2012; RIVM, 2006), indicating that even though cosmetics use might differ by culture, the amounts applied do not. With makeup products used on the lips, the present values for lipstick were the same as those of the RIVM (2006) but lower than the values reported by Loretz et al. (2005), Halls et al. (2007), and the SCCS (2012). There are no comparable existing data on lip gloss, but the present values were near the Western values for lipstick. Regarding the assessment of PCBs mentioned in the Introduction, the results of the present study do not change the original assessment of these products as "no problem" because the main target was makeup products containing pigments contaminated by PCBs as impurities. For cleansing products, the present study showed values for cleansing foam and makeup remover. The 90th percentile values were $2.19 \mathrm{~g} /$ day for cleansing foam and $3.15 \mathrm{~g}$ /day for makeup remover, which are almost the same as the existing data. These values are high as amounts applied, but as these products are rinsed off or wiped off when used, safety assessment needs to be carried out with the amount that actually remains on the skin. Using the applied amounts from the present study, it is possible to obtain exposure amounts with the retention coefficient given by the SCCS.

The present study yielded data on differences with respect to the existing data, which are mainly from the West, due to disparities in cosmetics customs as well as regional and climatic differences. It also provided information on exposure to categories of cosmetics for which information was previously insufficient. The data obtained are likely to be of great benefit not just in Japan but also in the increasingly globalized international community.

\section{Utilization of usage data in safety assessment (exposure assessment)}

The SED of a substance contained in a cosmetic product can be calculated by substituting the data on amount applied from the present study for product exposure in the following formula shown in the SCCS Guidance (SCCS, 2012): 
Actual consumption amounts of cosmetic products

$\mathrm{SED}=\mathrm{A}(\mathrm{mg} / \mathrm{kg}$ bw/day $) \times \mathrm{C}(\%) / 100 \times \mathrm{DAp}(\%) / 100$

With: SED (mg/kg bw/day) = Systemic Exposure Dosage $\mathrm{A}(\mathrm{mg} / \mathrm{kg}$ bw/day $)=$ Estimated daily exposure to a cosmetic product per kg body weight, based upon the amount applied and the frequency of application (the calculated relative daily exposure levels for different cosmetic product types)

$\mathrm{C}(\%)=$ The concentration of the substance under study in the finished cosmetic product on the application site

DAp $(\%)=$ Dermal absorption expressed as a percentage of the test dose assumed to be applied in real-life conditions

This formula is based on the dermal absorption rate, and can be used if data regarding the amount of product applied are used. The SCCS Guidance also puts forward another formula for calculation of SED, based on the level of dermal absorption per unit area. The SED can also be calculated using the rate of dermal absorption per unit area, as recommended by the SCCS Guidance, if dermal absorption experimental data are available. In this case, data on body surface area are needed.

For rinse-off products, assessment has to be carried out taking the relevant retention rate into consideration. Also, for products applied to the lips (lipstick, lip gloss), in which there is a likelihood of exposure via the oral route, the most conservative assessment is to assume that all of the product is absorbed orally, with $100 \%$ intestinal absorption. It is therefore appropriate in this case to calculate the SED by excluding 'Dermal Absorption (\%)/100' from the formula.

In order to assess the safety of chemical substances, exposure assessment scenarios that are as accurate as possible across a range of everyday settings must be envisioned. In recent years, there has been a demand for safety assessments not just of the raw materials of cosmetics but also of the systemic toxicity of impurities and carryover chemical substances present in the raw materials, taking into account exposure from multiple sources, such as the environment and household products. The present study focused on using exposure scenarios for safety assessments of cosmetic products, but as science advances, ensuring greater accuracy of cosmetics exposure assessments is significant not just from the point of view of safety assessments of cosmetics but also safety assessments for society in general.

In the present study, the amounts of cosmetic products consumed in Japan were surveyed during sum- mer and winter. The major conclusions of this study are summarized as follows: The present study showed that many people in Japan use items such as lotions, emulsions, facial mask packs, for which there are no Western exposure data, and also that the amounts of these items applied are comparatively large. The values for amounts of creams and essence applied were lower compared with the West. In the survey of sunscreen products, the results were classified according to daily use and outdoor leisure use, whereas the Western studies to date have not made this distinction. The results showed higher values for leisure use, but the values were still considerably lower than those in the West. There is a dearth of usable data on rinse-off products, but the present study has yielded applied amount data on cleansing forms. In addition, the amounts of makeup removers and makeup products applied were also similar to the Western data.

It is important to collect exposure data that match the respective cosmetics culture, and the data yielded by the present study will supplement the data on categories for which the data were insufficient in the past and will be useful information that can be applied to cosmetics exposure assessments. In addition, it will be possible to determine levels of systemic exposure to a given cosmetic ingredient by using the present amount applied data together with the concentration of the target ingredient in cosmetic products and data on dermal absorption rates. The present data are therefore indispensable for carrying out safety assessments of cosmetic products and will be extremely useful to regulatory authorities in Japan and around the world. Moreover, more accurate exposure assessments of cosmetic products are important not just from the perspective of the safety assessment of cosmetics but also for safety assessments of chemical substances in general.

Conflict of interest---- The authors declare the following potential conflict of interest: The authors belong to cosmetic corporation marketing cosmetics that are research objects. However, the survey itself was conducted by an independent laboratory as indicated in the manuscript.

\section{REFERENCES}

Aoyama, Y., Ito, A., Suzuki, K., Suzuki, T., Tanemura, A., Nishigori, C., Ito, M., Katayama, I., Sugiura, S. and Matsunaga, K. (2014): The first epidemiological report of rhododenol-induced leukoderma in Japan based on a nationwide survey. Jpn. J. Dermatol., 124, 2095-2109.

Bernard, A., Houssin, A., Ficheux, A.S., Wesolek, N., Nedelec, A.S., Bourgeois, P., Hornez, N., Batardière, A., Misery, L. and 
M. Yamaguchi et al.

Roudot, A.C. (2016): Consumption of hair dye products by the French women population: Usage pattern and exposure assessment. Food Chem. Toxicol., 88, 123-132.

Biesterbos, J.W.H., Dudzina, T., Delmaar, C.J.E., Bakker, M.I., Russel, F.G.M., von Goezt, N., Sheepers, P.T.J. and Roeleveld, N. (2013): Usage patterns of personal care products: Important factors for exposure assessment. Food Chem. Toxicol., 55, 8-17.

Chinuki, Y., Kaneko, S., Sakieda, K., Murata, S., Yoshida, Y. and Morita, E. (2011): A case of wheat-dependent exercise-induced anaphylaxis sensitized with hydrolysed wheat protein in a soap. Contact Dermatitis, 65, 55-57.

CTFA (Cosmetic, Toiletry, and Fragrance Association) (1983): Summary of the results of surveys of the amount and frequency of use of cosmetic products by women. CTFA Inc., Washington, D.C.

Hall, B., Tozer, S., Safford, B., Coroama, M., Steiling, W., Leneveu-Duchemin, M.C., McNamara, C. and Gibney, M. (2007): European consumer exposure to cosmetic products, a framework for conducting population exposure assessments. Food Chem. Toxicol., 45, 2097-2108.

Loretz, L.J., Api, A.M., Barraj, L.M., Burdick, J., Dressler, W.E., Gettings, S.D., Han Hsu, H., Pan, Y.H.L., Re, T.A., Renskers, K.J., Rothenstein, A., Scrafford, C.G. and Sewall, C. (2005): Exposure data for cosmetic products: lipstick, body lotion, and face cream. Food Chem. Toxicol., 43, 279-291.

Lundov, M.D., Opstrup, M.S. and Johansen, J.D. (2013): Methyl- isothiazolinone contact allergy-a growing epidemic. Contact Dermatitis, 69, 271-275.

Nishigori, C., Aoyama, Y., Ito, A., Suzuki, K., Suzuki, T., Tanemura, A., Ito, M., Katayama, I., Oiso, N., Kagohashi, Y., Sugiura, S., Fukai, K., Funasaka, Y., Yamashita, T. and Matsunaga, K. (2015): Guide for medical professionals (i.e., dermatologists) for the management of rhododenol-induced leukoderma. J. Dermatol., 42, 113-128.

Park, J.Y., Lee, K., Hwang, Y. and Kim, J.H. (2015): Determining the exposure factors of personal and home care products for exposure assessment. Food Chem. Toxicol., 77, 105-110.

RIVM (2006): Cosmetics Fact Sheet to assess the risks for the consumer Updated version for ConsExpo 4. RIVM report 320104001/2006. National Institute for Public Health and the Environment, Bilthoven.

SCCS (2012): The SCCS's Notes of Guidance for the Testing of Cosmetic Substances and Their Safety Evaluation, 8th Revision. Takano, K. (2015): Harmful phenomenon on cosmetics and history of cosmetic industries' efforts: from the case of melansis to the case of vitiligo. J. Jpn. Cosmet. Sci. Soc., 39, 17-22.

Tokura, Y., Fujiyama, T., Ikeya, S., Tatsuno, K., Aoshima, M., Kasuya, A. and Ito, T. (2015): Biochemical, cytological, and immunological mechanisms of rhododendrol-induced leukoderma. J. Dermatol. Sci., 77, 146-149.

US-EPA (2011): Exposure Factors Handbook: 2011 Edition. U.S. Environment Protection Agency, Washington, D.C. 